enterprise therefore has to be given some incentive in order to be confident of a reasonable profit", according to $\mathrm{Mr}$ William Bremer of Wisconsin University.

The Senate Subcommittee, however, has expressed concern at the 'monopoly' effect of issuing exclusive licences. It claims that although under both the present and projected form of the IPA, these are intended to be the exception rather than the rule, in practice most licences are granted on such a basis. A second concern is over who should decide whether a research worker should be granted a licence to develop a discovery he has made. In the initial draft of the new regulations, it was suggested that, in line with current practice at the NSF, this would require the agreement of the agency which had sponsored the research.

When this draft was sent out for comment, however, many universities reacted strongly against it, claiming that it would reduce the incentive for the individual research worker to report a potentially patentable discovery. The provision has now been dropped from the proposed regulations, raising the subcommittee's concern that universities may offer exclusive licences to a research worker rather than seeking outside, more appropriate, licensees.

Are there any alternatives to IPAs? William Carey, executive officer of the American Association for the Advancement of Science, together with others, feels that they should be dropped altogether as an unnecessary impedance on the flow of scientific ideas into the technological marketplace.

Subcommittee staff members are also looking at the possible appropriateness of a government agency such as the UK's National Research Development Corporation, which has a statutory responsibility to handle the patenting and licencing aspects of research carried out on government money including that funded in universities by the UK's research councils.

But at present any major innovation in patent policy, apart from the introduction of the new regulations, seems unlikely. Recognising the complexity of the issues-economic, political and legal-and the intensity of the motions that they raise the White House, for example, has steered clear of the area and it will not be part of a multiagency study of innovation announced recently. "The debate over government patent policy is a thicket a prudent man hesitates to enter," Mr Charles H. Herz, general counsel of the NSF, told the Senate Subcommittee. So it has been--and so it promises to remain.

David Dickson

\section{Friedrich Wöhler RIP}

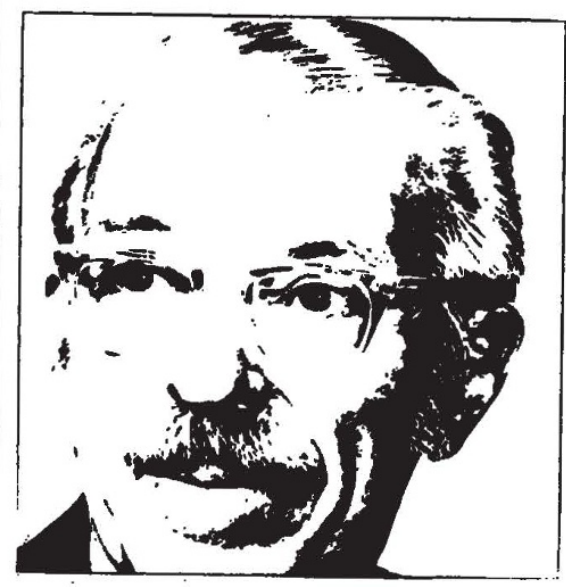

\section{THOMAS H. JUKES}

THIs year is the sesquicentennial of the announcement by Wöhler that marked the birth of synthetic organic chemistry. Earlier, Berzelius had formulated a concept that the numerous carbon compounds found in natural sources could be produced only by living organisms. "Elements in the organic world," said he, "appear to obey laws different from those in the inorganic world." His concept was the molecular equivalent of the dogma of spontaneous generation of life, a theory that had been put to death by the Abbé Spallanzani in the eighteenth century. As a result, the theory was, as Voltaire said, "rejected by whoever has studied nature at all". In like manner, Wöhler refuted Berzelius' theory by preparing urea from ammonia and carbon dioxide. In a sense, Berzelius' 'organic' chemistry was no longer organic. But the name persisted, and, as everyone except 'organic food' cultists should know, the term 'organic' properly refers to carbon compounds rather than to vegetables grown with the aid of animal manure.

The vitalists were not extinguished by Spallanzani, and, despite Voltaire's dismissal of their cause, they returned in 1858 to proclaim that spontaneous generation of animals and plants could be demonstrated in the laboratory. Pasteur promptly turned back their challenge with a series of famous experiments. One would have thought that, by 1978 , Wöhler's discovery would have convinced everyone that 'natural' compounds can be synthesized. But mythology is more persistent than veracity. Even the use of Wöhler's own compound, synthetic urea, which is used as a fertilizer, is challenged as not being equivalent to animal excreta for this purpose. The challengers have something to sell-a line of 'natural food' products. The selling job has been so pervasive that an extensive opinion survey in 1972 showed that $65 \%$ of the general public, and $52 \%$ of college graduates said "No" to the question, "Are man-made vitamins just as good as natural vitamins?"

Recently, at a meeting, when I pointed out that a synthetic vitamin is identical with its natural counterpart, a prominent Washington Post reporter said, "Your colleagues don't agree with you". To which I responded that, in this case, my colleagues would be wrong, and I asked her if she had ever heard of a mixed melting point. Of course she had not, and she was obviously not interested in my attempt to obfuscate the discussion by trotting out such scientific jargon.

'Natural', in terms of food, means a blessed surcease from hyperactivity in children, according to true believers. The proponent of this belief, Dr Ben Feingold, tells his followers that the statement "that the whole body is chemical; that all components of food are chemical" is "a somewhat ridiculous public relations argument of the additive industry," also that "not a single one of the synthetics used in our food has been subjected to the rigid investigations required for licencing drugs," which is quite untrue, because synthetic vitamins are used in both foods and drugs. The dietary treatment that he prescribes is based on elimination and exclusion of synthetic substances from the list of permitted foods. This procedure is a curious echo of the ancient ritualistic casting-out of demons from those who were possessed (and therefore hyperactive).

And 'natural' means profits. An officer of the Federal Trade Commission wrote recently of manufacturers who "do have a deep concern with their right to describe products as natural under the conditions described". I suspect that this deep concern may be connected with hope of sales. A vice-president of a large food company told me last month of his company's plans to test-market a new breakfast cereal which, he said, would be really natural, and contain "only natural vitamins". My attention wavered, and then vanished. But perhaps I should send him a copy of Ann. Physik. 12, 253 (1828) so that he can read about making urea without kidney, bladder, or lamp-post-seeking possessor thereof. 